\title{
EDITORIAL
}

\section{Does every psychopath have an antisocial personality disorder?}

\author{
Elias Abdalla-Filho, iD Birgit Völlm \\ Board, Forensic Psychiatry Section, World Psychiatric Association.
}

Amoral personality disorder; antisocial personality disorder; asocial personality disorder; dissocial personality disorder; psychopathic personality disorder; sociopathic personality disorder: these are expressions used in an unclear and perhaps even random way to refer to people who engage in behaviors that diverge from those expected by society.

Psychopathy is a subject of particular relevance in psychiatry, especially forensic psychiatry, and it gained greater attention after the introduction of the checklist created by Robert Hare, commented on below. ${ }^{1}$ However, it remains poorly delineated in clinical practice and this is compounded by the fact that psychopathy is not included in any of the current psychiatric diagnostic systems.

There is agreement that not every individual with an antisocial personality disorder (AsPD) is a psychopath. In fact, research shows that only one third of people with AsPD meet the criteria for psychopathy. ${ }^{2}$ However, how about the other side of the coin: Does every psychopathic individual have a diagnosis of AsPD? Many psychiatrists, including forensic psychiatrists, seem to believe that this is the case but there are few studies investigating the relationship between psychopathy and other personality disorders beyond AsPD.

Perhaps a look into history can help elucidate the answers to these questions. Schneider described psychopathy as a kind of nonspecific personality abnormality. ${ }^{3}$ In describing his ten types of psychopathic personalities, he did not confine himself to associating this concept with AsPD. On the contrary, he excluded antisocial behavior from the definition of psychopathy and argued for the existence of insensitive psychopathic individuals who are entirely sociable. To this author, psychopathic personalities would be those who, due to their abnormality, suffer and cause suffering in others. This differs from the current notion of psychopathy, which does not recognize the suffering of its bearer. This division of Schneider's types of psychopathic personalities provided support for the further classification of personality disorder types by both the ICD and the DSM. However, Schneider's classification did not include AsPD. The latter was added later in these two diagnostic systems, since its conceptual basis of behavior that is unacceptable to society was more sociological than psychological. In other words, Schneider

Correspondence: Elias Abdalla-Filho

E-mail: elias.abdalla@ terra.com.br

Submitted Oct 24 2019, accepted Nov 07 2019, Epub Feb 142020. focused on the centrality of personality while AsPD seems to be focused on the centrality of antisocial behavior. ${ }^{4}$

More recently, Blackburn conceived of psychopathy as being personality traits closer to narcissistic and histrionic personality disorders than to antisocial ones. ${ }^{4}$ According to him, some psychopathy criteria are found in AsPD (impulsivity, falsity, irresponsibility, lack of remorse), but others appear in other personality disorders of Cluster B (as well), notably narcissistic (grandiosity, lack of empathy), histrionic (exaggerated expression of emotion), and borderline (impulsivity). Blackburn was interested in a more in-depth study of psychopathy and, like Schneider, regardless of its links to criminal behavior, criticized overvaluation of the association between psychopathy and criminality.

Therefore, over time there has been a change of focus in the definition of psychopathy. It is no longer seen as a disorder causing psychological harm to its bearer, but to society. Consequently, psychopathy has become more associated with AsPD than with other personality disorders. The description of this specific personality type in the DSM-5 is basically behavioral. Although the ICD-10 criteria of dissocial personality disorder contain some affective elements, they do not address the broad affective and behavioral manifestations of psychopathy. ${ }^{5}$

It is very important to keep in mind that one of the most important scales for diagnosing psychopathy, the PCL-R created by Hare, consists of two correlated subfactors: the first (F1) is related to a selfish and remorseless use of others, and the second (F2) is related to a chronically unstable and antisocial lifestyle. Only the second subfactor is closely related to AsPD. The first subfactor, however, does not have a close relationship to that particular type of personality disorder. It is closer to the main features of psychopathy described by Cleckley in the 1940s. This author focused his attention on the discrepancy between apparent normality and the chaotic inner world of the psychopath. ${ }^{6}$

To some scholars, crime is more of a consequence than a diagnostic symptom of psychopathy ${ }^{4}$ and they advocate that it should be studied as separate from subfactor 2 of the PCL-R, which is not accepted by Hare. To Hare, antisocial and criminal behavior is a necessary diagnostic criterion for psychopathy.

How to cite this article: Abdalla-Filho E, Völlm B. Does every psychopath have an antisocial personality disorder? Braz J Psychiatry. 2020;42:241-242. http://dx.doi.org/10.1590/1516-4446-2019-0762 
As noted above, only one third of those with AsPD in the general population meet the criteria for psychopathy. Psychopathy is characterized by features that are not diagnostic criteria for AsPD, such as lack of empathy, arrogance and excessive vanity. ${ }^{2}$ Thus, not every psychopath necessarily has an antisocial personality disorder, but the construct psychopathy may include different traits of various types of personality disorders.

\section{Disclosure}

The authors report no conflicts of interest.

\section{References}

1 Hare RD. Without conscience: the disturbing world of the psychopaths among us. New York: Guilford; 1999.

2 Blair RJ. Neurobiological basis of psychopathy. $\mathrm{Br} J$ Psychiatry. 2003;182:5-7.

3 Schneider K. Clinical psychopathology. New York: Grune \& Stratton; 1959.

4 Blackburn R. Personality disorder and antisocial deviance: comments on the debate on the structure of the psychopathy checklist-revised. J Pers Disord. 2007;21:142-59.

5 Ogloff JR. Psychopathy/antisocial personality disorder conundrum. Aust N Z J Psychiatry. 2006;40:519-28.

6 Cleckley $\mathrm{H}$. The mask of sanity: An attempt to clarify some issues about the so-called psychopathic personality. 3rd ed. St Louis: CV Mosby; 1995. 